\title{
Time Features of Public Service Advertising Poster of Image
}

\author{
Yun Ding \\ Huanghe Science and Technology College \\ Zhengzhou, China
}

\begin{abstract}
After a certain relation between advertising and photography is established, photography has developed to use image as an art language to convey idea, emotion and public behavior, while previously it is designed only for products introduction. In contemporary art, it has become an independent art language. With the appearance of conceptual photography and its application in public service advertising poster, post-modern advertising has more abundant performance, and its connotative ideology enjoys popular support. The application of conceptual photography in print public service advertising has provided wide space for advertising creative.
\end{abstract}

Keywords-photography; advertising poster; public service advertising

\section{Public Service Advertising MaKs a Figure IN THE ERA OF SCIENCE AND TECHNOLOGY IN THE 20TH CENTURY}

In the 20th century, society and economy developed rapidly, but the ecological environment also deteriorated quickly. The reason is that human morality and public consciousness degenerate, and people immoderately develop the nature in pursuit of interest. At that time, the public service advertising, which can attract people's attention to living environment crisis and public consciousness crisis, was born at the right moment.

In 1940s, public service advertising appeared in America firstly. Public service advertising at that time is to help the public to know social problems, further influence their opinion and attitude to these problems, and facilitate the peace settlement of social problems. Established in 1971, Japanese public service advertising agency is dominated by enterprises, pays close attention to the people's livelihood and the contribution to society, and studies the most concerned problems of people, with the appeal theme closely related to hot spots of society [1] . In the 20th century, during the Second World War, the destruction brought by and the social environmental problems caused by social turmoil and dangerous weapons become the hottest theme of public service advertising at that time. Due to limited scientific level at that time, the main form of public service advertisings is poster, leaflet and radio broadcasting. Taking early advertising poster as an example, the earliest advertising poster was appeared in about 1000 BC. A handwritten text poster seeking for "runaway slave" and offering a reward appeared in Thebes, Ancient Egypt. In the 20th century, the development of advertising poster had gradually become mature. Many artists utilized poster to appeal to the government to stop the war and pursue human peace. For example, the poster "Victory in 1945", which was designed by Japanese artist Shigeo Fukuda in 1975 in memory of 30th anniversary after the end of World War II, depicts a bullet flying back to barrel in the form of cartoon. The utilization of visual arts is concise and humorous, satirizing that those start a war will finally eat their own bitter fruit. The implied meaning provokes deep thinking.

After the Second World War, various patterns of manifestation appeared in poster design. Conceptual photography is the most representative. The pop art style poster rising in late 1950s uses the mass culture concept to simply and popularly express its concept and convey information. For example, it uses mass language and expresses the female and male images more humorously, exaggerative and realistically through photography and poster, generating strong artistic appeal and visual impact. In $1960 \mathrm{~s}$, a batch of innovative and revolutionary artists appeared in Germany; the representative personages include Rambow, Van Desadn, Gunther Kieser, etc. They have created many creative poster design works--This is a kind of featured poster guided by originality and synthesized by photography photos. Most of poster works created by them are completed by photography. They decompose and combine reasonable images in daily life according to the requirement of works, create with photography photos, make the picture display unique, striking and shocking visual effect with means such as special effects of darkroom, comprehensive painting and air brush, and make the image finally displayed by works have profound metaphor and symbolizing effect[3]. In 1960s-70s, Peter Glaser, a famous American designer, paid attention to the combination of unique concept and information feature in his poster design, studied and utilized various expression methods and applied them into design works. He tried to create utilizing special effects of photography and montage in combination of means such as air brush and cut \& paste. He developed a school of his own and had so big an influence that he was followed by many designers. The application examples of early conceptual photography in poster design provide valuable experience for modern poster art.

The history of public service advertising is not long in China. It is believed that Chinese public service advertising 
activity starts from the "water conservation" public service advertising which was broadcasted by Guiyang TV station in 1986. And then, CCTV released the program of Publicize Widely in 1987. Public service advertising month has been held every year since 1996 under the direction of State Administration for Industry \& Commerce of the People's Republic of China. China's public service advertising started to boom since then [4]. The appearance of public advertising poster in China can be traced back to 1930 s, and was called "picture poster" at that time, which belongs to the category of artistic modeling [5]. In the beginning, public advertising poster mainly appears in the forms of handicrafts such as oil painting and print. Most works advocate the contents in the aspect of revolutionary politics and patriotism. After new China was established, a large batch of picture posters, with main contents showing great image of revolutionary leader, and presenting that workers and farmers actively devote into industrial and agricultural productive labor, and that PLA soldiers protect our homes and defend our country, spread all over urban and rural areas. In 1980s, a first batch of pictorial posters, which have a certain national features and try to break away from political nature, were appeared and obtained the approval and the support of government. For example, Green Comes from Your Hands, an environmental protection public service advertising poster works created by Chen Shaohua in 1984, obtained general consent of government, and obtained Gold Award in Pictorial Poster of National Fine Arts Exhibition and two Merit Awards. It is collected in the National Art Museum of China now.

Public advertising poster was truly developed in China after 1990s. Under the leadership of Deng Xiaoping, China witnessed high-speed economic development and continual improvement of scientific level; people's lives also have giant changes, and people's social consciousness increasingly increases. At the end of 20th century, Mr. Jin Daiqiang, a famous graphic design master in Hong Kong, combined traditional Chinese ink painting with photography image in his public service advertising poster design works such as "communication" and "care for nature", breaking through the traditional picture dominated Chinese advertising poster design.

\section{Public SERVICE AdVERtising DeVElops RAPIDLy UNDER TOHE BACKGROUND OF DIGITAL ERA ITN THE $21 \mathrm{TH}$ CENTURY}

Under the influence of digital background in the 21th century, the introduction of mass media makes more and more people join the new media and new technology, and participate in public utilities. At that time, traditional picture poster was gradually replaced by contemporary public poster due to its limitation, and public service advertising poster design started to click into place. Meanwhile, a batch of famous poster design masters and a series of excellent public service advertising poster design works were appeared, e.g., famous Hong Kong design master Mr. Jin Daiqiang who is famous for integrating traditional Chinese painting into design and his works Children "Fig. 1", and Mr. Chen Youjian who influences Chinese plane design with modern expression techniques such as combining Chinese and
Western cultures and adopting geometrical abstraction, character conception and line jumping. Mr. Chen Youjian's works reflects his unique understanding and pursuit for culture. For example, in the public poster New Beijing New Olympics which was designed by Chen Youjian in 2001 for bidding for the Beijing Olympic Games, the colors of five rings encircle a historic building--the Temple of Heaven; it both reflects the feeling of sports and highlights the regional feature of Beijing [7].

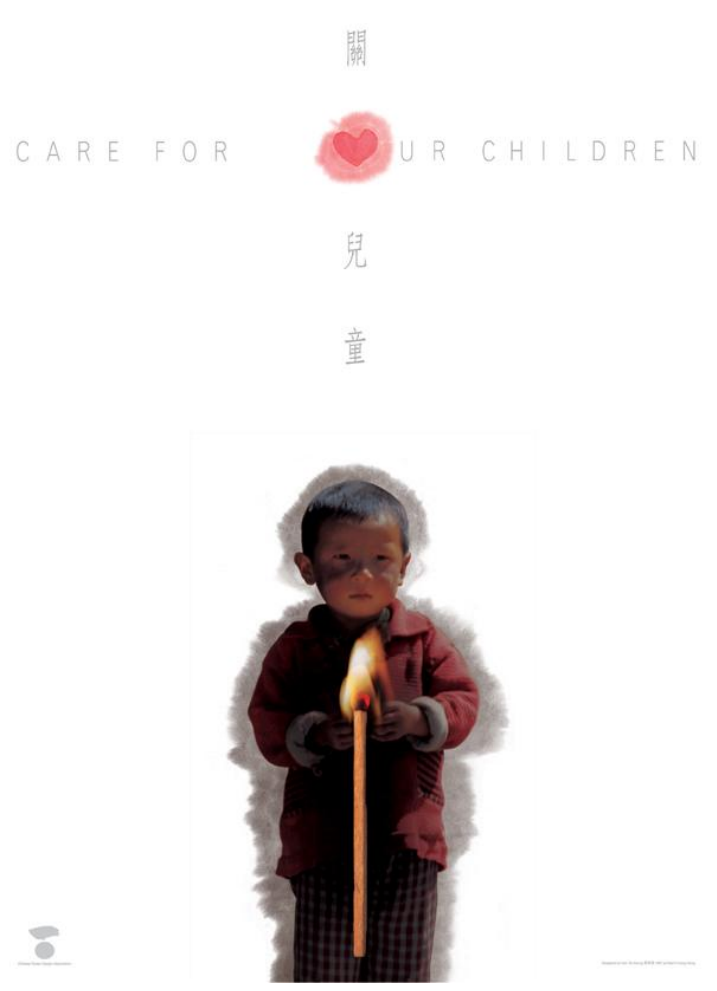

Fig. 1. Children (Source: Works of Jin Daiqiang)

In the 21 st century, the society is relatively stable, but the damage of human's living environment, ecological unbalance and social problems brought by excessive economic development speed have become the focus of domestic and overseas public advertising poster study nowadays. For example "Fig. 2" WWW environmental protection creative public advertising design works, when carefully observe this works, we can see that the handprint of opened two hands is in the shape of antelope, which heralds that the quantity of animals decreases progressively due to the change of ecological environment, and reminds people to protect our homeland with our hands.

In recent years, public service advertisings have received more and more attention. Lots of public service advertisings are appeared in TV advertisings, books and websites. Public service advertising has become a living culture and been accepted by the mass as a living culture. Public service advertising design with poster as an example is especially valued by the designers and even colleges and universities. In design competitions such as National Art Design 
Competition for College Students, Taiwan "Golden Calf" design competition, creativity competition for college students, public advertising poster has become an independent category; moreover, in higher education, most design students select public service theme in advertising poster design.

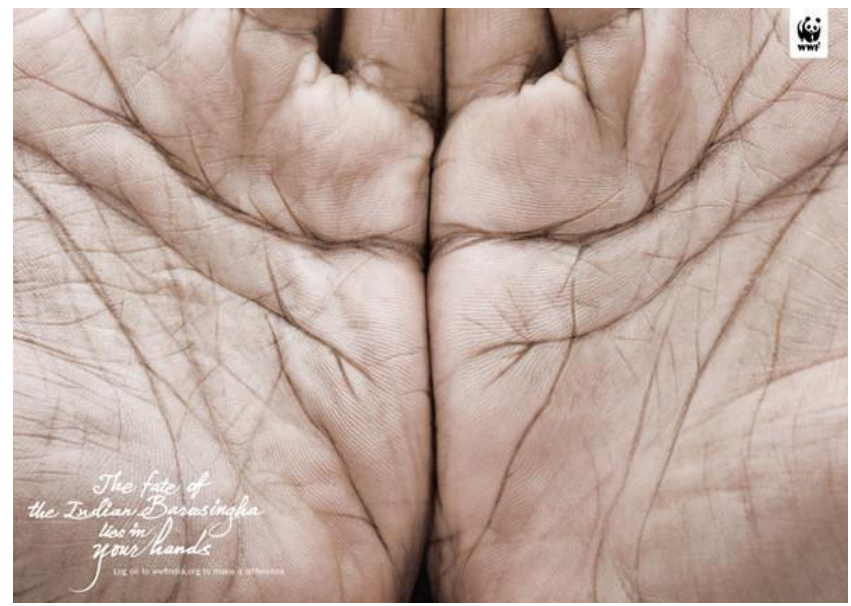

Fig. 2. WWF environmental protection creative public advertising design (Source : http://shijue.me/show_text/500019e0ac1d840b93007060)

\section{New Public Service AdVertising of IMAGE REAPPEARS UNDER THE BACKGROUND OF CONTEMPORARY ART}

Under contemporary art background, since visual image shows the "actual" "existence", using visual image as ontology language, conceptual photography is gradually praised highly and applied by artists as a new type image. Meanwhile, photography is widely applied to advertising poster design as an important technique of expression in advertising design. In essence, as public service advertising, photography shall be reduced to artistic creation. However, since it possesses the functionality of advertizing, it belongs to advertising design and becomes an important medium and means of public service advertising communication. In the courses of Advertising Photography and Advertising Design, many art colleges and universities encourage the students to create boldly and closely combine new photography language with public service advertising. Their works not only is novel but also possesses a certain connotation, drawing great attention from the society. For example, in Nestle Coffee Advertizing Series "Fig. 3"-- a works of student Chen Wei, the works integrates some literary quotations (such as, "head of the thigh" and "cone beam") in traditional Chinese culture with the theme of "refresh" of Nestle coffee. The appeal of works makes people have the feeling of striking the table and shouting bravo.

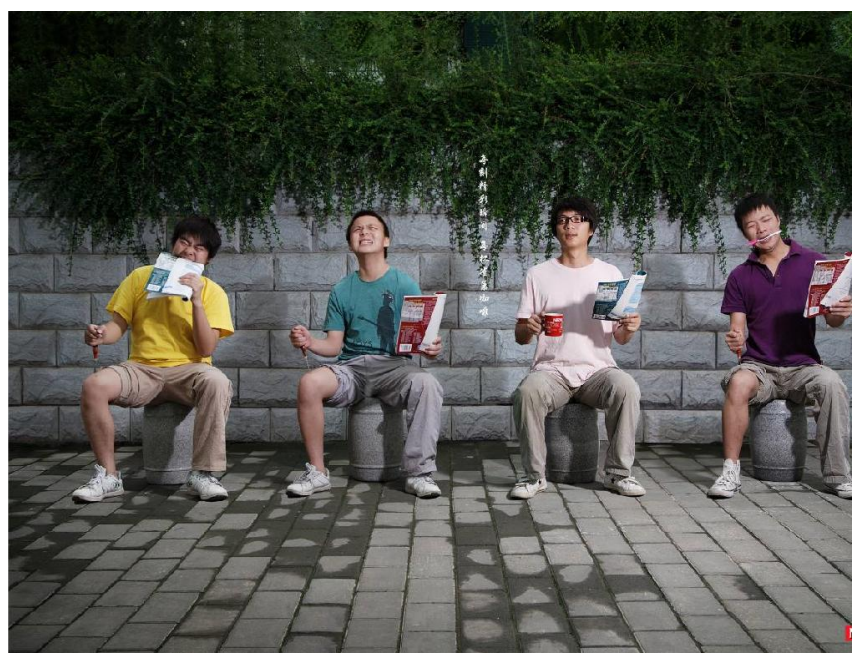

Fig. 3. Nestle Coffee Advertizing Series Source : Works of Chen Wei

In advertising poster design, the appearance of photography expression not only broadens the representation space of modern poster design, meanwhile, it can truly represent the object, truly and objectively reflect the object. Photography can capture some instantaneous images beyond one's imagination. Through utilizing multiple ways of expression, shooting skills, darkroom technology and computer post-processing, etc., photography can objectively presents morphological characteristics of objects, such as form, color, texture or local detail, and can also subjectively reflect the presence principle of object and create artistic conception needed by designer. Some special effects can be generated through utilizing different techniques of photography. For example, different lenses, wide angle, long lens, zoom and changing shooting angle can be used to exaggerate and deform object and make people see different contents from normal vision; utilization and controlling of exposure, multiple exposure or moving camera can produce special effects such as image overlapping and dynamic effect; using different cameras, such as traditional film camera, LOMO camera and view camera, can control the overall effect of picture; unexpected special effect can be accidentally generated through conducting various explorations utilizing darkroom technology in combination of traditional arts \& crafts. All these cannot be compared by other design representation forms. At present, it has become one of main patterns of manifestation in poster design.

\section{CONCLUSION}

Various advertisements emerge in the surging economic tide and compete with each other. Compared with other media, the intuition, sense of reality, transmissibility and art aesthetics of photography advertising are better. Compared with photography advertizing, even if the so called "hyperconcentration, hyperspace, superstrong expression" TV advertising only has more dynamic and sound, but is significantly inferior in many aspects such as timeliness, convenience and economy [8]. The intuition and authenticity of photography photo have greatly narrowed the 
psychological distance between works and audience. Its application in public service advertising poster design can easily obtain the audience's trust, generate strong attraction to audience's vision, and achieve the final effect of moving. Photography occupies an important position in public service advertising [9]. Seen from advertizing design, photography satisfies the fast and precise requirement of advertizing design. In addition, creative conceptual photography provides lots of materials for advertizing, powerfully expands the creation, design, production, release and dissemination field of advertizing, and improves the overall level of advertizing design.

\section{REFERENCES}

[1] Bao Kun. Review [M]. Beijing: China Literary Federation Press. 2009.352,31,31.

[2] Wang Qingsong. Role of Photography in Advertizing Design [J]. Literature and Art for the Populace. 2010,(1): 132.

[3] Tang Yiyong. Poster Design [M]. Shanghai. Shanghai People's Fine Arts Publishing House.31-33

[4] Lu Chunhong, Rao Qin. Discussion on Development History of Public Service Advertising in China [J]. Brilliant Works.2011.25

[5] Zhang Jie. A Thought on the Publicity of Contemporary Public Posters [J]. Art Panorama.2009.7

[6] Chen

Shaohua. Baidupedia[EB/OB].http://baike.baidu.com/view/764232.htm

[7] Chen Hong, Zhu Heping. Research on Poster Design Style Features of Hong Kong Godfather Alan Chan [C]. Jingdezhen Comprehensive College Journal.2010.12

[8] Zhai Xiao. Advertising Photography in Market Economy [EB/OL]. (2006-11-2).

[9] http://www.cphoto.net/Html/syll/gysy/16495964. html.

[10] Wang Qingsong. Role of Photography in Advertizing Design [J]. Literature and Art for the Populace. 2010, (1): 132 